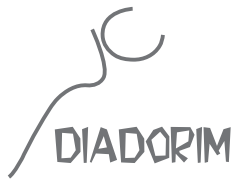

GUimarÃES, Maria Severina Batista; CAMARGO, Goiandira Ortiz de. Adélia Prado e a poética da ressalva. Revista Diadorim / Revista de Estudos Linguísticos e Literários do Programa de Pós-Graduação em Letras Vernáculas da Universidade Federal do Rio de Janeiro. Volume 15, Julho 2014. [http://www.revistadiadorim.letras.ufrj.br]

\title{
ADÉLIA PRADO E A POÉTICA DA RESSALVA
}

\author{
Maria Severina Batista Guimarães ${ }^{1}$ \\ Goiandira Ortiz de Camargo ${ }^{2}$
}

\section{RESUMO}

A recorrência com que um autor utiliza certos recursos estilísticos para transpor em linguagem sua experiência constitui um dos aspectos de sua poética. Em Adélia Prado, os temas mais recorrentes de sua obra já foram bastante explorados pela crítica, considerando que se trata de uma poeta bastante lida e muito estudada nos meios acadêmicos. O estudo que ora apresentamos nesse artigo pretende ser mais uma contribuição para sua fortuna crítica, ressaltando um aspecto relevante que perpassa por toda sua temática: a recorrência com que a poeta utiliza os conectivos adversativos, principalmente o mas, o que dá a sua poesia um sentido de ressalva, uma forma de redenção da condição feminina.

PALAVRAS-CHAVE: Poética; condição feminina; experiência; discurso.

\section{ABSTRACT}

The recurrence with an author uses certain stylistic resources to features to incorporate in your language experience is its poetics. In Adelia Prado, the most recurring themes of his work have already been well explored by critical, considering that it is a very well read poet and studied in academia. The study that we present in this article is intended to be one more contribution to its critical fortune, highlighting an important issue that permeates throughout its theme: the recurrence with the poet uses the adversative connectives, but mostly, what gives his poetry one sense of caveat, meaning of redemption of thefeminine condition. KEYWORDS: Poetry; womanhood; experience; speech.

1. Maria Severina Batista Guimarães é professora da UniversidadeEstadual de Goiás - UEG. [mrsvrnbtstgmrs. guimares@gmail.com]

2. Goiandira Ortiz de Camargo é professora da Universidade Federal de Goiás - UFG e pesquisadora do CNP -PQ 2. [g.ortiz@uol.com.br] 
Minha mãe cozinhava exatamente: arroz, feijão-roxinho, molho de batatinhas.

Mas cantava.

Adélia Prado

Por muitos anos a maioria das mulheres viveu num universo limitado pela sua condição social. Presas entre bordados e catecismos ou envolvidas com afazeres domésticos repetitivos, seu mundo girava em torno da satisfação dos filhos e do marido. Nesse universo carregado de restrições, o sujeito sente uma carência da realização interior e exterior, de materializar seus desejos, sonhos e pensamento e constituir o mundo à sua maneira. Porém, nem sempre é possível essa harmonia e, assim, a vida pode caminhar para a negação, dor em que o ser se desdobra, se debate em busca de uma liberdade que só se realiza isoladamente de forma limitada e finita. Os momentos de vida plena são raros e efêmeros, alcançados por meio de subterfúgios que causam mais culpa que prazer. Essa dor de existir em condições adversas está presente na poesia de Adélia Prado como um fadário da condição feminina.

Pode-se ler na poesia adeliana um profundo desejo de se redimir dessa predestinação, o que só parece possível por meio de um olhar profundo e atento para o exíguo espaço do cotidiano e ver em cada detalhe da casa, das tarefas diárias, das conversas perdidas em meio a suspiros, um sentido maior de inserir nesse espaço outra visão, desvelando o que em tudo isso pode ser a ressalva do ser que emerge dessas contingências:

\author{
A tão criticável tristeza \\ e seu divisível ser \\ pelejam por abotoar em mim \\ seu colar de desespero. \\ Mas eu peço perdão:
}

a Deus e a vós, irmãos.

(PRADO, 1991, p. 228, grifo nosso)

De acordo com o dicionário de Antônio Houaiss, "ressalva" é uma observação escrita para emendar o que se escreveu erradamente ou para tornar válida a inserção de outra palavra ou trecho. $\mathrm{O}$ sentido conferido ao verbo "ressalvar", no mesmo dicionário, leva-nos mais perto de onde queremos 
chegar: livrar de responsabilidade ou culpa, de perigo ou dano, eximir, desculpar-se, justificar-se. É nesse sentido que afirmamos ser a poesia feita por mulheres, mais expressivamente a de Adélia Prado, uma poética da ressalva, ou seja, uma forma de se redimir, quase de se desculpar da exiguidade de seu universo, mas, ao mesmo tempo, de reparar o dano que o gênero feminino sofreu durante anos de opressão, em que foi sempre considerado inferior ao homem. É como se fosse uma emenda ao que se escreveu erradamente, uma palavra nova nesse espaço tradicionalista em que a mulher esteve sempre na contramão.

Para tanto, a figura retórica que melhor dá conta dessa dialética lírica é a antítese, porém num sentido um pouco mais amplo do que o comumente usado de abrigar oposições. É por meio dos contrastes que a voz feminina procura compensar os limites apertados de seu espaço social, dando ênfase nas ressalvas, em que os conectivos adversativos concentram o significado, expandindo o sentido de um verso e, ao mesmo tempo, restringindo e limitando o enunciado anterior, como nos poemas que seguem:

Um homem habitou uma casa

\section{$[\ldots]$}

Eu comia assim:

arroz, feijão, cebola crua, mas o prato tinha a beirada bordada.

A colher oxidava, mas no cabo, miosótis gravados.

$[\ldots]$

(PRADO, 1991, p.223, grifos nossos).

Como se pode ler nesses versos, há sempre algo que salva da mediocridade essa mulher limitada ao espaço restrito da casa. De qualquer "canto da casa", o eu sonhador pode buscar na imaginação os lugares mais distantes, "onde moram: toda riqueza do mundo e minha alma", como diz um verso do poema do último trecho citado. O ser feminino se salva pelos detalhes e a ressalva é onde se estabelece a visão poética, um ângulo do qual se pode vislumbrar a beleza. Nesses importantes detalhes, a alma feminina vai encontrando seu ser e se identificando com o mundo, transformando-o com sua visão poetizada. Não importa que seu universo tenha se restringido aos limites da casa e aos afazeres domésticos, pois sua capacidade de transcendência supera a cotidianeidade e libera a vida dos estreitos limites pela iluminação poética. A culinária pode ser uma arte e um meio de realização pessoal tanto para o homem 
como para a mulher, porém cozinhar arroz com feijão e batatinha só pode ter um significado maior para alguém cuja alma paira acima dessa contingência e se eleva pela contemplação que a faz cantar.

Os miosótis gravados no cabo da colher só são signos da redenção para os mais sensíveis, cujo olhar não se circunscreve ao objetivo, cuja fome não é só material. A poesia, como os miosótis no cabo de uma colher enferrujada, dá sentido à vida daqueles que ainda se sensibilizam com a beleza, a qual se sobrepõe ao banal. Arroz, feijão e cebola crua são detalhes que deixam realçar as flores bordadas na beirada do prato. Assim, o ciclo se completa nessa poética da ressalva. O codificado se descodifica e se recifra, conferindo ao poema e à vida uma nova significação, a reescritura permanente sob uma perspectiva única. Ao leitor e à leitora, cabe a graça de ver o mundo por uma perspectiva nova e de exercitar seu próprio poder criador, identificando-se mais intensamente com esse universo feminino poetizado, com essa revisão do mundo ao qual se insere uma palavra nova, sendo conduzido por essa retórica em que o jogo dos contrários instala a diferença fundamental de sentido do discurso e da vida. O que se diz não é tudo que se quer dizer, pois o inusitado da combinação dos enunciados convoca o leitor a expandir seu sentido. Assim, a voz da mulher que fala na poesia adeliana, mostrando esse universo feminino, está longe do conformismo que limita o ser a um estreito cotidiano, pois a visão se expande para além dele pela via da criação, da capacidade de apontar o olhar para as mínimas coisas que podem levar à transcendência do sujeito.

Nas formas líricas mais puras, como as canções românticas, a parataxe é a frase poética preferida. Já a lírica moderna se permite construções sintáticas em que as conjunções aparecem como elo entre as orações, criando uma estrutura mais lógica, diminuindo o efeito lírico e cedendo lugar à fala. Staiger (1997) aponta como "talvez um traço feminino da poesia lírica, ou um traço lírico da mulher" esse estilo de poemas "exclusivamente musicais", com economia dos conectivos ou da pontuação. Adélia nega esse modelo de poesia ao costurar seus versos com as conjunções - principalmente as coordenativas - e dar a eles uma respiração mais longa e menos cadenciada. A conjunção "mas" (e suas equivalentes) denotam basicamente a ideia de oposição, restrição ou contraste ao que já foi dito, ligando orações ou períodos com a mesma estrutura sintática. Depois de uma afirmativa, a conjunção introduz a ressalva, limitando ou retificando o enunciado, diminuindo sua relevância. Geralmente enuncia-se uma opinião ou declaração que causa surpresa ou espanto, pois além da ideia básica de oposição e contraste, a partícula "mas" apresenta outros valores, como restrição, retificação, atenuação, compensação ou mesmo adição (CUNHA, s/d). O emprego marcante dessa partícula na poesia de Adélia Prado é no sentido de retificação, atenuação e compensação, como se pode perceber nos poemas citados.

Para afirmar a ideia acerca de uma poética da ressalva, é preciso considerar a importância da retórica, ou seja, dos recursos empregados pela linguagem poética como uma arte ligada a um estilo e, 
mais particularmente, a figuras que tornam literário um texto. No presente estudo, considera-se retórica como a articulação dos argumentos e do estilo com função de persuadir não apenas pelas ideias, mas pela beleza do dizer, usando o discurso literário como um tecer ardiloso que desvia a linguagem de seu uso comum para explorar seu poder de atração e impacto. Sendo assim, os recursos empregados têm a dupla função de convencer e de tornar o texto artístico. Portanto, o olhar poetizado para o mundo exige uma linguagem nesse mesmo nível, anulando a distância entre o que se vê e o que se diz, entre o presente e o passado, entre o trivial e o sublime. Por outro lado, o que se diz não é em vão, a voz lírica que soa como uma manifestação da alma quer penetrar em outra alma, quer comunicar algo e tocar o outro, despertar suas emoções e sensibilidade para a beleza da vida e da linguagem, para a poesia, enfim.

Uma tendência da poesia lírica contemporânea é seu espírito crítico, em que o poema se autointerpreta, dizendo algo sobre si mesmo e sobre o eu que se expressa por essa via. Nesse sentido, a poética de vários autores contemporâneos explica a si mesma por meio de seus poemas autorreflexivos, como esse de Adélia Prado que ressalta a importância da linguagem e das ressalvas:

A poesia, a salvação e a vida

Eu vivo sob um poder

Que às vezes está no sonho, no som de certas palavras agrupadas, em coisas que dentro de mim refulgem como ouro:

a baciinha de lata onde meu pai fazia espuma com pincel de barba.

De tudo uma veste teço e me cubro.

Mas, se esqueço a paciência, me escapam o céu e a margarida-do-campo.

(PRADO, 1991, p.217, grifo nosso)

O eu lírico que fala no poema assume sua condição de poeta e reflete sobre seu fazer como resultado de um poder que vem de uma memória involuntária e também da força das palavras. Todavia, para desenvolver essa dádiva, é preciso uma participação efetiva do sujeito lírico, há um mas ressalvando a condição de existência da poesia centrada no trabalho paciente da poeta. Para captar no 
espaço do sonho e dentro de si mesma as coisas que "refulgem como ouro", é preciso a abertura do ser para perceber nas pequenas coisas um sentido mais profundo de existir. Essas imagens de sonho se materializam pela força da palavra poética, traduzida num certo modo de agrupá-las, a fim de trazer de novo ao coração o que está guardado na memória. Assim, a poesia lírica se torna expressão de uma subjetividade que se salva por esse meio:

Eu não sei o que é,

mas sei que existe um grão de salvação

escondido nas coisas deste mundo.

(PRADO, 1991, p.218, grifo nosso)

Analisar os processos retóricos torna-se, em alguns casos, um fundamento básico para a apreensão mais ampla do sentido do fenômeno poético, pois à literatura cabe criar a sua arte transformando uma matéria de segunda em matéria-prima. A poesia é feita com as mesmas palavras usadas para se comunicar no dia a dia, as quais a/o poeta tem que agrupar de forma nova para alcançar o efeito desejado. Umberto Eco (1995) aponta um aspecto da retórica interessante para a análise das ressalvas adelianas, que são os mecanismos argumentativos com base em recursos dialéticos. Tais recursos, que consistem, a grosso modo, em apresentar oposições possíveis de se desfazer numa síntese, em Adélia põem em jogo o significado da experiência acrescentada à imaginação, associando forma sensível e fantasia, o que resulta num discurso que é fruto dessas junções. A figura retórica apropriada para estabelecer a dialética é a antítese por estabelecer essa oposição retórica entre elementos e, como já foi dito, muito utilizada por Adélia Prado, sendo foco dessa análise.

Não se trata aqui da retórica baseada nos sofistas, ou seja, a falsa adulação ou indução a inverter valores, trata-se de outra retórica, a que se baseia numa argumentação rigorosa e profunda não com a intenção de dominar, mas de defender-se, de ressalvar com base numa lógica surpreendente. Seu discurso não se reduz à função de convencer alguém de alguma coisa, trata-se de retificar, de desnudar algo que ficou oculto, que deve vir à luz para que as coisas sejam postas no lugar certo, que é o lugar do poético. Aristóteles é quem primeiro nos dá a ideia da dialética por meio da retórica, pois, apesar de atribuir-lhe um papel mais modesto, mostra que ela é indispensável para uma situação de incertezas e conflitos, os quais não podem ser resolvidos senão pela força do debate contraditório. Nesse processo, busca-se reduzir o outro ao silêncio por meio de suas contradições ou pela surpresa e impacto de uma afirmação inusitada. Assim, a dialética é a arte do diálogo ordenado a partir do provável, respeitando 
uma certa lógica em busca não especificamente da verdade, mas de uma opinião aceita. Não importa se a tese seja verdadeira ou não, o que importa é se o jogo linguístico foi efetivado de modo a produzir efeito no outro. A dialética é um jogo intelectual que não está diretamente ligado ao processo do fazer artístico do discurso, mas os dois se cruzam em intersecção, pertencendo ao mesmo mundo que não é o absoluto das ciências e nem o incognoscível do sagrado. A retórica, como prática dialética, fica entre esses opostos como possibilidade de conhecer sem provas irrefutáveis, não só pelo logos - a razão -, mas também pelo ethos e pelo pathos. Esses conceitos já estão em Aristóteles como sendo os três elementos fulcrais do discurso, ou seja, o caráter do enunciador (ethos), as paixões despertadas no leitor/ ouvinte (pathos) e o próprio discurso (logos). Maingueneau (2004) discute esse conceito aristotélico de ethos e o amplia:

Mas esse ethos não diz respeito apenas, como na retórica antiga, à eloquência judiciária ou aos enunciados orais: é válido para qualquer discurso, mesmo escrito. Com efeito, o texto escrito possui, mesmo quando o denega, um tom que dá autoridade ao que é dito. Esse tom permite ao leitor construir uma representação do corpo do enunciador (e não, evidentemente, do corpo do autor efetivo). A leitura faz, então, emergir uma instância subjetiva que desempenha o papel de fiador do que é dito. (MAINGUENEAU, 2004, p.98).

A esse "fiador" que emerge do texto poético os críticos chamam de eu lírico e essa subjetividade não é senão a capacidade do locutor de se colocar no texto como um ego, sendo este apenas um estatuto linguístico da pessoa que se pronuncia no discurso, organizando a experiência e o conhecimento. Como não há um conceito próprio da entidade eu, o significado dessa palavra se refere ao sujeito do ato do discurso no qual aparece como uma representação do suposto diálogo (AGAMBEN, 2008).

Sendo o sujeito apenas o locutor, nunca será possível apreender o estatuto da experiência muda, original, no sentido apontado por Giorgio Agamben (2008), pois o sujeito se constitui pela linguagem. Dessa forma, nos tempos modernos, um dos pontos de intersecção dos diversos discursos e, portanto, dos diversos sujeitos, é o uso das figuras de linguagem. Desde os tempos antigos que o uso dessas figuras foi considerado como uma forma de "exprimir-se de modo marcante, com encanto e emoção." (REBOUL, 2004), assinalando a subjetividade do discurso. No entanto, na modernidade elas foram usadas indiscriminadamente até pela propaganda, chegando mesmo a uma certa banalização de seu emprego, o que exige maior criatividade por parte dos escritores que pretendam preservar a originalidade desse uso. 
Não é possível introduzir um conceito das figuras sem nos remeter à noção de desvio proposto nos anos de 1960, considerando a retórica restrita ao uso figurado da linguagem e aproximando-a da literatura. O desvio é uma noção bastante polêmica, pois a pergunta é: desvio em relação a quê? De acordo com os adeptos dessa teoria, o desvio se dá em relação a um "grau zero da escrita" (BARTHES, 2000), ou seja, ao falar denotativo em que o significante se liga diretamente a um significado. Na metáfora, por exemplo, o sentido é desviado do sentido próprio para um semelhante por uma livre associação de sentido.

Considerando a literatura, e especialmente a poesia, um uso peculiar da linguagem, sua singularidade se funda principalmente nos desvios que pratica em relação ao código linguístico usual (COHEN, 1966). Assim, todo desvio consiste num jogo entre as convenções e sua subversão. Para entrar nesse jogo, é preciso entender a linguagem em suas diferentes funções, principalmente a denotativa, ligada ao referencial, ao intelecto, e a conotativa, ligada à emotividade, adequada à expressividade poética e ao jogo retórico.

A força da imagem engendrada nas figuras de linguagem permite encontrar a expressão mais justa e mais vivaz, subtraindo-se da função meramente comunicativa e utilizando "um signo definido pela ausência de signo e cujo valor é perfeitamente reconhecido, pois está inserido num sistema de figuras em que essa ausência se torna sentido pleno" (GENETTE, 1972, p. 200). O estatuto da figura não é muito claro na tradição retórica, pois, ao mesmo tempo em que afirma tratar-se de um falar fora do comum, obscuro, essa organização linguística é o único meio de desvelar o real, daí a sua natureza oracular. Assim, as figuras tornam a fala uma escolha muito particular, um falar distinto que marca o estilo, tornando-o mais nobre ou mais criativo, conferindo-lhe beleza e originalidade que não passa despercebida ao leitor atento. A grosso modo, pode-se dizer que a figura nasce da separação entre o signo e o sentido, é a "erva que nasce na greta do muro", usando a imagem criada por Adélia Prado (1991, p.78) e tira o leitor de seu conforto racional, causando-lhe surpresa e obrigando-o a buscar sentido por outra via, fora da referencialidade. Sendo assim, as figuras estão ligadas à duplicidade da linguagem: por trás do que se diz emerge sempre outro significado, como num palimpsesto, fundando uma outra ordem, uma lógica inesperada e surpreendente, pois traz em si uma ausência e uma presença.

Se, por um lado, a linguagem do poema remete para um conteúdo, para algo que existe independente da expressão verbal, sendo que "as palavras são simples substitutos das coisas" (COHEN, 1966, p.31), por outro, a palavra poética busca trazer a coisa mesma para a presença: "Assim escrevo: tarde. Não a palavra./ A coisa” (PRADO, 1991, p.261), num desejo de alcançar a indissociabilidade entre significante e o significado. Para Octavio Paz, o sentido aponta para as coisas, assinala-as, mas jamais as alcança, pois os objetos estão mais além das palavras, por isso a linguagem figurada tem esse poder de tornar a coisa presente pela força da imagem. Por essa visão, parte-se da ideia de que a realidade em si mesma é neutra, nem prosa, nem poesia, a linguagem é que a constituirá uma coisa ou outra com a força de sua expressão retórica. 
Sem ignorar toda a discussão possível em torno de uma "poética das coisas", não se pode ignorar que muitos poetas modernos mostraram que poesia se faz "ao rés do chão", com as coisas mais banais, pois a poesia não está no que se diz, mas na maneira de dizer, "no som de certas palavras agrupadas". Nesse sentido, a ressalva de Adélia no poema citado anteriormente serve para mostrar que sua poética se firma num projeto bem delineado, o qual procura resgatar a poeticidade das coisas mais simples por meio de uma linguagem específica, elaborada de forma a fazer com que a imagem refulja em meio a um discurso aparentemente referencial. Assim, sua poesia alcança um liame entre a vida cotidiana e a sublimidade da visão artística ao produzir o efeito de contradição entre seus elementos.

Um dos temas fundantes da poesia de Adélia Prado é a religiosidade, que aparece também ressalvada por uma dialética em que o erotismo associa-se ao elemento contraditório em busca de uma síntese entre os prazeres do corpo e o êxtase da alma pela via mística. No poema "Paixão de Cristo", do livro Oráculos de maio (1999, p.55), pode-se ler esse percurso ascético pelo caminho da escatologia, iniciado e finalizado com ressalvas:

\author{
Apesar do vaso \\ que é branco, \\ de sua louça \\ que é fina, \\ lá estão no fundo, \\ majestáticas, \\ as que no plural \\ se convocam: \\ Fezes. \\ Para que me insultem \\ basta um grama \\ de felicidade: \\ 'baixe o tom de sua voz, \\ não acredite tanto \\ em seu poder'. \\ O martírio é incruento \\ Mas a dor é a mesma.
}

(grifos nossos) 
A aceitação da precariedade humana pela via da paixão, no sentido de sofrimento, coloca o ser em seu devido lugar com expressão nas ressalvas: apesar das aparências, a realidade a que somos convocados a enfrentar todos os dias exige que sejamos humildes. Mesmo que esse martírio existencial não cause nenhuma ferida física, a dor de existir nessa condição precária é como caminhar sobre pedras com os pés descalços ou ser coroado de espinhos. Admitindo que, apesar de tudo, é preciso baixar o tom da voz em sinal de humildade, o indivíduo quer marcar posição, como diz no poema "Direitos humanos", do mesmo livro:

\author{
Sei que Deus mora em mim \\ como sua melhor casa. \\ Sou sua retorta alquímica \\ e para sua alegria \\ seus dois olhos. \\ Mas esta letra é minha. \\ (PRADO, 1999, p.73, grifo nosso)
}

Ao poeta cabe o ato da elocução. Das quatro partes da retórica (a heurésis, a taxis, a léxis e a hypocrisis, segundo Reboul), a léxis é a que mais se aproxima da produção literária, pois é preciso contar com a disposição do escritor em investir na ação de colocar em palavras o que antes é apenas uma visão, um vago sentimento ou uma ideia e ainda conferir essa voz a um eu que não seja o eu empírico. Buscar a expressão mais impactante, mais convincente, mais encantadora, essa é a retórica dessa poesia que é pura decantação do verbo, mas é também uma instância subjetiva que quer comunicar algo.

Sendo assim, o ethos do enunciador precisa estar imbuído de autoridade. Nesse poema, a ressalva é para afirmar certa autonomia da criatura em relação ao Criador, a consciência de sua participação na criação da obra, pois a incompreensão dos mistérios e das contradições do universo não impedem o ser de usufruir certo bem-estar que ameniza a dor da paixão:

\author{
Podem gritar \\ as cigarras \\ e as serras dos carpinteiros. \\ Nunca serão funestas, \\ fatiam a tarde
}


que continua inconsútil.

O mundo é ininteligível, mas é bom.

(PRADO, 1999, p.69, grifo nosso)

Percebe-se que o eu lírico alcança uma iluminação pela via poética, a qual é muito parecida com a via mística, pois a poesia é "uma face de Deus estampada nas coisas do mundo". Dessa forma, pode-se concluir que tanto a poesia quanto a religião são ressalvas para o ser humano se redimir e se elevar de sua condição precária de estar no mundo. Mesmo para a morte há uma ressalva:

\section{$[\ldots]$}

A morte veio e vem, mas se deve alçar os caixões

e com passo de marcha carregá-los, chorando sim,

Mas como quem leva espigas para o campo.

(PRADO, 1999, p.216, grifo nosso)

Considerando que a poeta mineira fala geralmentede um ambiente doméstico, há um amálgama de opostos num sentido mais profundo que nem sempre se conciliam, provocando um anseio de transcendência que só se realiza em raros momentos em que o eu lírico se liberta das restrições e adversidades desse espaço e dessa condição. A solução definitiva de todas as contradições, a liberdade plena, o ser só alcança no domínio de uma totalidade, uma unidade suprema da esfera absoluta do espírito, o que só é possível na religião e na arte, segundo Hegel (1993). Para a mulher, essa totalidade é ainda mais inatingível, pois, sendo o outro em relação ao universal (BEAUVOIR, [19--]), tal condição instaura uma falta angustiante diferente do ser masculino, sempre considerado o centro. Ter sido silenciada por séculos de repressão em uma sociedade que procurou anular sua personalidade confere a seu canto um tom de lamento do ser banido: a que transita em sentido contrário ("Não sabes ler a placa? É CONTRAMÃO” (PRADO, 1991, p.56)). É desse lugar periférico que ecoa a voz que ainda enxerga nessa exiguidade o que há de redentor para esse ser marginalizado em busca de uma identidade: 


\author{
$[\ldots]$ \\ Eu não sei quem sou. \\ Sem me sentir banida experimento degredo. \\ Mas não recuso os marimbondos armando suas caixas, \\ porque são alegres como posso ser, \\ são dádivas, \\ mistérios cuja resposta agora é só uma luz, \\ a pacífica luz das coisas instintivas. \\ (PRADO, 1991, p.247, grifo nosso)
}

Não recusar as dádivas e os mistérios da existência é aceitar a compensação de que, mesmo não tendo um lugar de referência com o qual se identifique, o eu lírico busca a alegria, pois há uma luz em cada ser, "a pacífica luz das coisas instintivas", que propicia um saber natural e anterior à razão para guiá-lo.

Alguns estudiosos afirmam que a casa, durante muitos séculos da história grega, foi o espaço feminino por excelência. Nela a mulher cumpria as tarefas domésticas que lhe cabiam: tecer as roupas e guarnições, costurá-las e, muitas vezes, bordá-las, cozinhar, limpar e lavar. Nesse espaço, prevaleciam as leis dos homens que tinham como objetivo manter as mulheres sob controle, as quais eram consideradas seres volúveis, sem capacidade de controlar seus impulsos, uma força tão imprevisível quanto a natureza. Todavia, supõe-se que tenha havido em alguns lugares, como Lesbos, um raro grau de igualdade social entre homens e mulheres, uma considerável liberdade sexual pelo menos para jovens aristocráticas, as quais tinham acesso a um sistema educacional que as preparava inclusive para o casamento (RAGUSA, 2000). Um dos maiores castigos do ser humano era viver na ignorância e afastado da poesia e da música, castigo que não raro era imposto às mulheres. Marginalizadas e excluídas, elas não aprendiam a ler e a escrever, com exceção das cortesãs e das nobres. Acredita-se que Safo tenha composto poemas oralmente, não escreveu poemas no sentido moderno. Por isso, a revolução cultural que abre espaço para as mulheres representa uma mudança na história da literatura que ainda não foi devidamente avaliado. $\mathrm{O}$ que se pode perceber mesmo sem pesquisas aprofundadas é que hoje temos um número relativamente grande de mulheres escrevendo livros em prosa e poesia, um tipo de arte que só se conjuga com a suprema liberdade no dizer. E é isso que se pode constatar na obra dessas autoras: projetos poéticos bem delineados em que a liberdade de tratar temas como erotismo e religião 
demonstram que a mulher de hoje está livre de certas contenções, das regras rígidas da moralidade que uma organização social baseada em valores machistas criou como padrão comportamental.

Sendo assim, a poesia é uma forma de representação capaz de revelar a unidade que permite a subsistência de todas as diferenças entre as partes. É o espaço onde as criaturas se recriam e recriam o mundo numa relação que se avizinhe, o máximo possível, da verdade absoluta, por isso a subjetividade presente na poesia feita por mulheres revela a presença de um ser que busca se reconhecer por meio de sua própria história e da memória familiar, como expressa Adélia Prado nesse poema:

\section{Fotografia}

Quando minha mãe posou

para este que foi seu único retrato,

mal consentiu em ter as têmporas curvas.

Contudo, há um desejo de beleza em seu rosto

que uma doutrina dura fez contido.

A boca é conspícua,

mas as orelhas se mostram.

O vestido é preto e fechado.

O temor de Deus circunda seu semblante,

como cadeia. Luminosa. Mas cadeia.

Seria um retrato triste

se não visse em seus olhos um jardim.

Não daqui. Mas jardim.

(PRADO, 1991, p.230, grifos nossos)

Mais uma vez confirma-se no poema de Adélia Prado sua poética da ressalva: a adversativa "mas" inicia três orações e sua equivalente "contudo" estabelece o jogo dialético em que o poema se constrói, introduzindo orações que soam como uma compensação ou uma emenda à afirmação anterior. Alguma coisa guardada na intimidade desse ser, cuja aparência se estampa na fotografia, é autêntica. O olhar atento para um simples retrato três por quatro desvela o universo interior mal disfarçado pelos recatos da época. O retrato seria triste "se não visse em seus olhos um jardim", que, embora seja de outro mundo, é um jardim. Assim, a essência dessa mulher fica resguardada nesse outro plano, o da 
exceção, que a visão poética trata de revelar. O ser marginalizado encontra uma via por onde pode se afirmar como sujeito além das realidades aparentes.

O eu lírico presente no texto aponta uma realidade social de determinada época por marcas que vão se evidenciando como símbolos de um tempo em que à mulher eram negadas as manifestações mais íntimas. Todo o poema está contaminado de signos e, portanto, de ideologia. Cada um desses signos delimita um campo semântico e os fenômenos ideológicos que os constituem. Segundo Bakhtin (1997), a cadeia ideológica se estende de uma consciência à outra, num processo de interação social, tomando a palavra como o recurso semiótico que possibilita o desenvolvimento da consciência individual do discurso interior para a consciência social como ato ideológico. Nenhum discurso soa no vazio, ele está sempre subvertendo ou reforçando outras vozes. A dialogia estabelecida no poema faz chegar ao leitor duas vozes: a de uma geração de mulheres emudecidas, sem direito a manifestações pessoais, que falam por meio dos sinais ressignificados pela voz de outra geração, a da filha, que não esconde o desejo de retorno ao paraíso perdido. A primeira ressalva do poema, iniciada pela conjunção adversativa "contudo", chama a atenção para o desejo de alegria que o sistema não conseguiu apagar, a boca se destaca pela beleza discreta, mas as orelhas que poderiam estar escondidas se mostram numa evidência de ostentação. No verso "O vestido é preto e fechado" não há apenas uma descrição em que o substantivo vestido vem seguido de um adjetivo que o determina. A cor preta tem toda uma carga significativa que não existiria em outro contexto. "Fechado" não é só contrário de "aberto" em relação ao vestido, mas em relação a todo o sistema social em que a mulher se insere. A posição da cabeça também denuncia a repressão e o desejo contido.

Muitos princípios, normas sociais e imposições sofridas pelas mulheres são forjados nos dogmas da religião, que prega a submissão feminina até hoje. Na fotografia em foco, o semblante da mulher é marcado por um oximoro que evidencia o contraste de forma irônica, ressalvada pela comparação e pela oposição semântica entre o substantivo e o adjetivo: cadeia luminosa. É dessa cadeia que emerge o ser desejante do retorno ao jardim paradisíaco que se sobrepõe a tudo que poderia ser um retrato triste da condição humana.

Assim, a leitura que o eu lírico faz do signo social, que é a fotografia, desentranha um ser que se esconde e se mostra nos signos ideológicos. O retrato é uma marca no presente que traz as evidências da opressão sofrida no passado. O temor de Deus contrasta com o desejo de beleza pressentida no rosto, desejo que os valores éticos e morais reprimiram e que o olhar perscrutador da filha desvela. A religião, como uma doce cadeia, propõe um retrato da circunspecção, da imposição de dogmas que imprimem a tristeza, porém os olhos denunciam a possibilidade de uma transcendência que a religião não proporciona, de um lugar apenas intuído, mas capaz de redimir o ser. Essa é a ótica do sujeito que 
olha o mundo além das aparências, com as devidas ressalvas. Os olhos são a entrada para a alma e é lá que o sujeito desse discurso penetra para sua leitura profunda dos emblemas contidos no corpo. Há um desejo de alegria no eu que é transposto para o objeto olhado, tornando-o o signo de uma relação que é pessoal e ao mesmo tempo social e ideológica. A palavra poética restaura esse ser embutido em outro signo e registra as transições mais íntimas, todas as nuances do ser circunscrito em determinado momento histórico, mas ultrapassa essa contingência e eleva esse ser a um estágio superior, em que sua essência fala de uma existência contida nas limitações que o rosto denuncia e disfarça ao mesmo tempo. Assim, a fotografia de que fala o poema é o retrato de toda uma geração de mulheres determinadas socialmente por valores morais e éticos que procuravam suprimir os desejos mais verdadeiros do ser feminino, uma "doutrina dura" que impôs seus signos e normas de comportamento que não deviam nunca ser transgredidas. Mas foram. A duras penas, mas foram.

\section{Artigo recebido: 20/01/2014}

\section{Artigo aceito: 10/05/2014}

\section{Referências}

AGAMBEN, Giorgio. Infância e história: destruição da experiência e origem da história.Trad. Henrique Burico. Belo Horizonte: editora UFMG, 2008.

BACHELARD, Gaston. O ar e os sonhos. Tradução de Antonio de Pádua Danesi. São Paulo: Martins Fontes, 1990.

A água e os sonhos: ensaio sobre a imaginação da matéria. Tradução de Antônio de Pádua Danesi. São Paulo: Martins Fontes, 1997.

. A poética do espaço.Tradução de Rosemary Costhek Abílio. São Paulo: Martins Fontes, 1993.

BAKHTIN. M. Marxismo e filosofia da linguagem: problemas fundamentais do método sociológico na ciência da linguagem. Tradução de Michel Lahud e Yara frateschi Vieira. 8a edição. São Paulo: Hucitec, 1997.

A estética da criação verbal. Tradução de Maria Ermantina Galvão. 3ª edição. São Paulo: Martins Fontes, 2000.

BARTHES, Roland. O grau zero da escrita: seguido de novos ensaios. Tradução de Mário Laranjeira. São Paulo: Martins Fontes, 2000.

BEAUVOIR, Simone de. O segundo sexo. Tradução de Sérgio Milliet. Rio de Janeiro: Nova Fronteira, $19[--]$. 
COHEN, Jean. "O problema do poético". In: Estrutura da linguagem poética. Trad. Álvaro Lorencini e Anne Arnichand. São Paulo: Cultrix, 1966.

CUNHA, Celso. Nova gramática do português contemporâneo. Rio de Janeiro: Nova Fronteira, s/d. ECO, Umberto. Interpretação e superinterpretação. Trad. MF. São Paulo: Martins Fontes, 1993. . Os limites da interpretação. Trad. Pérola Carvalho. São Paulo: Perspectiva, 1995.

GENETTE, Gerard. Figuras. Trad. Ivonne F. Mantoanelli. São Paulo: Perspectiva, 1972.

HEGEL, G. W. Friedrich. Estética. Trad. Álvaro Ribeiro e Orlando Vitorino. Lisboa: Guimarães Editores, 1993.

MAINGUENEAU, Dominique. Discurso Literário. Trad. Eduardo Brandão. São Paulo: Editora Contexto, 2009.

.Análise de textos de comunicação. Trad. Eduardo Brandão.São Paulo: Editora Cortez, 2004.

PAZ, Octavio. Os filhos do barro. Trad. Olga Savary. São Paulo: Nova Fronteira, 1984. A outra voz. In.: A outra voz. Trad. Wladir Dupont. São Paulo: Siciliano, 1993, p. 133-148.

PEDROSA, Celia. "Poéticas do olhar na contemporaneidade". In. Revista Literatura e Sociedade. № 8 São Paulo: USP/ FFLCH/DTLLC, 2005.

PRADO, Adélia Poesias reunidas. São Paulo: Siciliano, 1991.

RAGUSA, Giuliana. Fragmentos de uma deusa: a representação de Afrodite na lírica de Safo. Campinas:UNICAMP, 2005.

REBOUL, Olivier. Introdução à retórica. Trad. Ivone Castilho Benedetti e Dão Paulo: Martins Fontes, 2004.

RICOEUR, Paul. Metáfora e símbolo. In: Teoria da interpretação: o discurso e o excesso de significação. Trad. Artur Mourão. Lisboa: Edições 70, s/d.

SAMPAIO, Maria Lúcia Pinheiro, Processos retóricos na obra de João Cabral de Melo Neto. São Paulo: ILHPA-HUCITEC, 1980.

STAIGER, E. Conceitos fundamentais de poética.Trad. Celeste Aída Galeão. Rio de Janeiro: Tempo Brasileiro, 1997. 